AKÜ FEMÜBID 17 (2017) $\mathbf{0 3 5 5 0 3}$ ( 1019-1029)

AKU J. Sci. Eng. 17 (2017) 035503 (1019-1029)

DOi: $10.5578 / \mathrm{fmbd} .66171$

\title{
Comparative Analysis of Least-squares Approaches for 3D Datum Transformation in Western Turkey
}

\author{
Mevlut GULLU, Mustafa YILMAZ, Tamer BAYBURA \\ Afyon Kocatepe University, Engineering Faculty, Geomatics Engineering, Afyonkarahisar, TURKEY. \\ e-posta:mgullu@aku.edu.tr
}

\begin{tabular}{|c|c|}
\hline & \\
\hline $\begin{array}{l}\text { Keywords } \\
\text { 3D datum } \\
\text { transformation; Least- } \\
\text { Squares (LS); Total } \\
\text { Least-Squares (TLS); } \\
\text { Weighted Total Least- } \\
\text { Squares (WTLS). }\end{array}$ & $\begin{array}{l}\text { In Turkey, the national reference frame was changed for geodetic applications in parallel with the } \\
\text { increasing use of Global Navigation Satellite System technology. Due to the reference frame change, } \\
\text { the three-dimensional (3D) datum transformation has become compulsory between ED50 and WGS84. } \\
\text { Several 3D datum transformation algorithms have been developed for geodetic applications. The well- } \\
\text { known technique is the Least-Squares (LS) method. In this study, alternative 3D datum transformation } \\
\text { approaches (including the Total Least-Squares (TLS) and the Weighted TLS (WTLS) methods) were } \\
\text { compared with the LS method over a test area. The results showed that the WTLS transformed 3D } \\
\text { coordinates with better accuracy than the LS and TLS methods. }\end{array}$ \\
\hline
\end{tabular}

\section{Türkiye'nin Batısında 3B Datum Dönüşümü için En Küçük Kareler Yaklaşımlarının Karşılaştırma Analizi}

\begin{tabular}{cl} 
Anahtar kelimeler & Özet \\
\cline { 2 - 2 } 3B datum dönüşümü; & Türkiye'de, Global Uydu Konumlama Sistemi teknolojisinin artan kullanımına paralel olarak, ulusal \\
En küçük kareler (EKK); & referans sistemi değiştirilmiştir. Referans sistemi değişikliğine bağlı olarak, ED50 ile WGS84 arasında üç- \\
Toplam en küçük & boyutlu (3B) datum dönüşümü zorunlu hale gelmiştir. Jeodezik uygulamalar için çeşitli 3B datum \\
kareler (TEKK); Ağırlıklı & dönüşüm algoritmaları geliştirilmiştir. En iyi bilinen teknik En-Küçük Kareler (EKK) dır. Bu çalışmada \\
toplam en küçük & alternatif (Toplam En-Küçük Kareler (TEKK) yi ve ağırlıklı TEKK (ATEKK) yi içeren) 3B datum dönüşüm \\
kareler (ATEKK). & yaklaşımları bir test alanında EKK yöntemiyle karşılaştırılmıştır. Sonuçlar ATEKK nin 3B koordinatları EKK \\
& ve TEKK yöntemlerinden daha doğru dönüştürdüğünü göstermiştir. \\
\hline
\end{tabular}

(c) Afyon Kocatepe Üniversitesi

\section{Introduction}

The geodesy is the scientific discipline that deals with the determination and depiction of the Earth's geometry, gravitational field, and rotation in a three-dimensional (3D) time-varying space. The first (geometry) pillar of geodesy is remarking to determine the Earth's size and geometric shape with the utmost precision. The geometry of the Earth deals with the determination and the presentation of precise 3D positions by establishing and maintaining the geodetic reference networks.
The geodetic networks are comprised of reference points distributed on the surface of the Earth to materialise the geodetic reference systems for the geospatial positioning (Pearlman et al. 2006).

Nowadays, with the advent of space-based techniques, Global Navigation Satellite Systems (GNSS) (GPS, GLONASS, and the upcoming Galileo) have become the leading positioning tools for establishing geodetic reference networks because for providing highly accurate location and time information anywhere on the Earth. GNSS (by a 
majority, GPS) measurements are extensively used for the determination of 3D coordinates in geodetic applications. World Geodetic System 1984 (WGS84) is a spatial reference frame for GPS measurements; however, to materialize the utilization of WGS84, countries using different datum have to change the datum to WGS84 or perform a datum transformation to WGS84.

The Turkish National Geodetic Network (TNGN) was established between 1934 and 1954 by the General Command of Mapping using conventional techniques. TNGN was based on the European Datum 1950 (ED50). Until 2001, all coordinate information and cartographic products produced nationwide used the TNGN (e.g., legal cadastral and property rights). However, this reference frame is not well suited to the tectonic structure of Turkey, nor was it adequate for modern GNSS-based geodetic applications. Therefore, Turkish National Fundamental GPS Network (TNFGN) was introduced by the General Command of Mapping in 2001 (Turgut 2010).

The TNFGN is based on 600 stations, of which 145 were re-surveyed in 2003 and 172 were re-surveyed in 2004. In addition, a 2005 reconnaissance of $\sim 210$ points was performed for the improvement and maintenance of TNFGN. The 3D coordinates and associated velocities of each station were computed in ITRF2000 with periodic GPS measurements and transformed into ITRF96 (Ayhan et al. 2002; Caglar 2005; GCM 2014). Subsequent comparisons between WGS84 and ITRF validate that the two reference systems are identical with differences being statistically insignificant for most practical purposes. The difference is of the order of cms (NGA 2002; Schwieger et al. 2009). TNFGN coordinates can be considered as WGS84 coordinates for geodetic, mapping and surveying applications (Ayhan et al. 2002). The reference frame change in Turkey make compulsory 3D datum transformation between ED50 and WGS84.

The classical Least-Squares (LS) method has been generally used for the linear estimation problems (e.g., coordinate transformation) in geodesy, surveying, and photogrammetry (Tong et al. 2011). Golub and Van Loan (1980) introduced the Total Least-Squares (TLS) method for the errors-invariables (EIV) model and it was solved by Teunissen (1988) in an exact geodetic form. Since the introduction of this method, widespread attention has been given to both TLS and Weighted TLS (WTLS) applications for datum (coordinate) transformation task in geodesy (Akyilmaz 2007, Schaffrin and Feuls 2008, Mahboub 2012, Li et al. 2013, Fang 2014, Mihajlović and Cvijetinović 2016, Zhao 2016).

The primary objective of this paper was the comparison of the LS, TLS, and WTLS transformation methods over a test area by using a set of 3D cartesian coordinates of the control points. First, the theoretical reviews of 3D datum transformation and LS approaches were described. Subsequently, the test area, data acquisition, and the evaluation methodology were outlined. The comparative transformation study is detailed. The outputs from both methods were interpreted to figure out the future studies.

\section{Theoretical Background}

The computation of the corresponding of the coordinate information produced in a coordinate system in another coordinate system is called "coordinate transformation". The coordinate transformation is used in the geodetic datum transformation, in dealing with the datum shifts for deformation analysis, in the conversion of cartographic products to a different coordinate system, and in the calculation of the field coordinates of the image coordinates for photogrammetric applications.

In order to perform coordinate transformation, common points whose coordinates are known in both coordinate systems are required. If there are enough common points, the computations may be carried out with the help of the direct formulas as the similarity transformation (Gullu 2016). If there are more than enough common points, the adjustment computations come onto the agenda and the parameters that will be used in transformation are calculated with the help of the adjustment process. The transformation 
parameters are predicted by accepting the design matrix used in forming the functional model of the LS method as errorless and assuming that the measurements are at the same accuracy (Gullu et al. 2003). However, there are coordinate values as well as constant values used in the design matrix. These coordinates contain systematic and random errors. The parameters are estimated in the LS method by assuming that these errors do not exist (Ghilani and Wolf 2006).

In the TLS method in which the coordinates of the common points are accepted as erroneous, corrections are made to the constant values and to the coordinates in the coefficients matrix used for the functional model. Furthermore, the transformation parameters are estimated assuming that the coordinates are at the same accuracy (Van Huffel 1997, Golub and Van Loan 1980, Felus 2004). The WTLS method is formed with the inclusion of the weights obtained from the variance-covariance values (of the coordinates that are used in the TLS method) in the adjustment model. An iterative algorithm is used in the WTLS method for the coordinate transformation. When the difference between the predicted parameters reaches an acceptable value, the iteration ends and the transformation parameters are estimated (Felus and Schaffrin 2005, Fang 2011, Jazaeri et al. 2013). The seven-parameter (3D) transformation model is defined as:

$\left[\begin{array}{l}X \\ Y \\ Z\end{array}\right]=\left[\begin{array}{l}t_{x} \\ t_{y} \\ t_{z}\end{array}\right]+k\left[\begin{array}{ccc}1 & -\varepsilon_{z} & \varepsilon_{y} \\ \varepsilon_{z} & 1 & -\varepsilon_{x} \\ -\varepsilon_{y} & \varepsilon_{x} & 1\end{array}\right]\left[\begin{array}{l}x \\ y \\ z\end{array}\right]$

where $(X, Y, Z)$ are the target system coordinates, $(x, y, z)$ are the original system coordinates, $\left(t_{x}, t_{y}, t_{z}\right)$ are axis translation parameters, $\left(\varepsilon_{x}, \varepsilon_{y}, \varepsilon_{z}\right)$ are axis rotation angles, and $k$ represents the scale factor (Fig. 1).

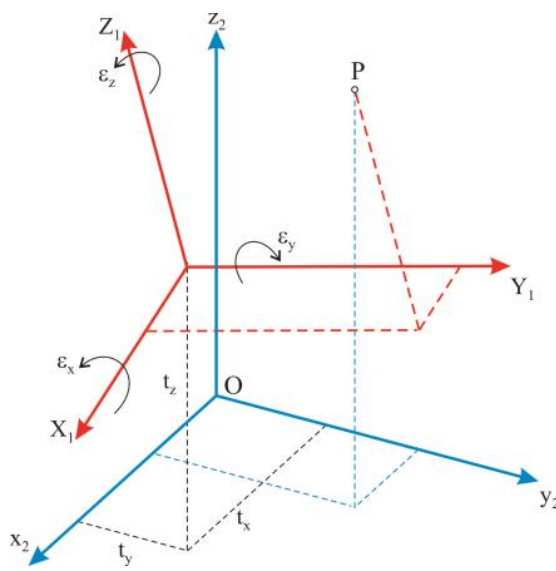

Fig. 1 Seven-parameter similarity transformation.

If the Eq. (1) is re-organized, the following equation is obtained:

$\left[\begin{array}{l}X \\ Y \\ Z\end{array}\right]=\left[\begin{array}{ccccccc}1 & 0 & 0 & 0 & -z & y & x \\ 0 & 1 & 0 & z & 0 & -x & y \\ 0 & 0 & 1-y & x & 0 & z\end{array}\right]\left[\begin{array}{c}t_{x} \\ t_{y} \\ t_{z} \\ \varepsilon_{x} \\ \varepsilon_{y} \\ \varepsilon_{z} \\ k\end{array}\right]$

The Eq. (2) is valid for a single point. There must be enough common points $(\geq 3)$ for estimating the parameters. If the Eq. (2) is re-organized for the $n$-number of common points, the following general equation is obtained for the coordinate transformation (Ren et al. 2015).

$\left[\begin{array}{c}X_{1} \\ Y_{1} \\ Z_{1} \\ X_{2} \\ Y_{2} \\ Z_{2} \\ \vdots \\ X_{n} \\ Y_{n} \\ Z_{n}\end{array}\right]=\left[\begin{array}{ccccccc}1 & 0 & 0 & 0 & -z_{1} & y_{1} & x_{1} \\ 0 & 1 & 0 & z_{1} & 0 & -x_{1} & y_{1} \\ 0 & 0 & 1 & -y_{1} & x_{1} & 0 & z_{1} \\ 1 & 0 & 0 & 0 & -z_{2} & y_{2} & x_{2} \\ 0 & 1 & 0 & z_{2} & 0 & -x_{2} & y_{2} \\ 0 & 0 & 1 & -y_{2} & x_{2} & 0 & z_{2} \\ \vdots & \vdots & \vdots & \vdots & \vdots & \vdots & \vdots \\ 1 & 0 & 0 & 0 & -z_{n} & y_{n} & x_{n} \\ 0 & 1 & 0 & z_{n} & 0 & -x_{n} & y_{n} \\ 0 & 0 & 1 & -y_{n} & x_{n} & 0 & z_{n}\end{array}\right] \quad\left[\begin{array}{c}t_{x} \\ t_{y} \\ t_{z} \\ \varepsilon_{x} \\ \varepsilon_{y} \\ \varepsilon_{z} \\ k\end{array}\right](3)$

The essential matrices for the adjustment computations are formed from the Eq. (3); 


$$
\begin{aligned}
A & =\left[\begin{array}{ccccccc}
1 & 0 & 0 & 0 & -z_{1} & y_{1} & x_{1} \\
0 & 1 & 0 & z_{1} & 0 & -x_{1} & y_{1} \\
0 & 0 & 1 & -y_{1} & x_{1} & 0 & z_{1} \\
1 & 0 & 0 & 0 & -z_{2} & y_{2} & x_{2} \\
0 & 1 & 0 & z_{2} & 0 & -x_{2} & y_{2} \\
0 & 0 & 1 & -y_{2} & x_{2} & 0 & z_{2} \\
\vdots & \vdots & \vdots & \vdots & \vdots & \vdots & \vdots \\
1 & 0 & 0 & 0 & -z_{n} & y_{n} & x_{n} \\
0 & 1 & 0 & z_{n} & 0 & -x_{n} & y_{n} \\
0 & 0 & 1 & -y_{n} & x_{n} & 0 & z_{n}
\end{array}\right] \\
l & =\left[\begin{array}{c}
X_{1} \\
Y_{1} \\
Z_{1} \\
X_{2} \\
Y_{2} \\
Z_{2} \\
\vdots \\
X_{n} \\
Y_{n} \\
Z_{n}
\end{array}\right] \quad x=\left[\begin{array}{c}
t_{x} \\
t_{y} \\
t_{z} \\
\varepsilon_{x} \\
\varepsilon_{y} \\
\varepsilon_{z} \\
k
\end{array}\right]
\end{aligned}
$$

where $A$ represents the coefficients matrix, I represents the measurements vector, and $x$ represents the unknown quantities vector. The unknown quantities may be estimated after the solution of the normal equations; however, since the coordinate values in $A$ and $l$ matrices are very large, the normal equations will become quite large. This will disrupt the condition of the normal equation coefficients matrix. Therefore, the generalized $A$ and $l$ matrices must be used. For this purpose, the deviation amounts from the centroid of the common point coordinates may be used as:

$\bar{x}_{i}=x_{i}-x_{m}$

$\bar{y}_{i}=y_{i}-y_{m}$

$\bar{z}_{i}=z_{i}-z_{m}$

where $\left(x_{i}, y_{i}, z_{i}\right)$ represent the common point coordinates used in transformation, $\left(x_{m}, y_{m}, z_{m}\right)$ represent the centroid of the common point coordinates, and $\left(\bar{x}_{i}, \bar{y}_{i}, \bar{z}_{l}\right)$ represent the deviation amounts from the centroid (Gullu et al. 2003, Lan et al. 2012). If the Eq. (4) is re-organized; the following equation is obtained:

$$
\begin{aligned}
& A=\left[\begin{array}{ccccccc}
1 & 0 & 0 & 0 & -\bar{z}_{1} & \bar{y}_{1} & \bar{x}_{1} \\
0 & 1 & 0 & \bar{z}_{1} & 0 & -\bar{x}_{1} & \bar{y}_{1} \\
0 & 0 & 1 & -\bar{y}_{1} & \bar{x}_{1} & 0 & \bar{z}_{1} \\
1 & 0 & 0 & 0 & -\bar{z}_{2} & \bar{y}_{2} & \bar{x}_{2} \\
0 & 1 & 0 & \bar{z}_{2} & 0 & -x_{2} & \bar{y}_{2} \\
0 & 0 & 1 & -\bar{y}_{2} & \bar{x}_{2} & 0 & \bar{z}_{2} \\
\vdots & \vdots & \vdots & \vdots & \vdots & \vdots & \vdots \\
1 & 0 & 0 & 0 & -\bar{z}_{n} & \bar{y}_{n} & \bar{x}_{n} \\
0 & 1 & 0 & \bar{z}_{n} & 0 & -\bar{x}_{n} & \bar{y}_{n} \\
0 & 0 & 1 & -\bar{y}_{n} & \bar{x}_{n} & 0 & \bar{z}_{n}
\end{array}\right] \\
& l=\left[\begin{array}{c}
\bar{X}_{1} \\
\bar{Y}_{1} \\
\bar{Z}_{1} \\
\bar{X}_{2} \\
\bar{Y}_{2} \\
\bar{Z}_{2} \\
\vdots \\
\bar{X}_{n} \\
\bar{Y}_{n} \\
\bar{Z}_{n}
\end{array}\right] \quad x=\left[\begin{array}{c}
t_{x} \\
t_{y} \\
t_{z} \\
\varepsilon_{x} \\
\varepsilon_{y} \\
\varepsilon_{z} \\
k
\end{array}\right]
\end{aligned}
$$

\section{LS method}

The measurements made on physical earth contain systematic and random errors. These errors may be reduced to an acceptable (negligible) level; however, they can never be eliminated completely. $n$ indicates the number of the measurements, $u$ indicates the number of the unknown quantities; and, $n-u=0$ symbolizes a measurement issue, $n-u>0$ symbolizes an adjustment issue, and $n-$ $u<0$ symbolizes a problem with infinite solutions. The purpose of the adjustment computations is to determine the exact values of the unknown quantities by using more measurements. During the time of this process, the measurements need to be corrected by measurement residuals $(v)$. The objective function of the LS method can be constructed as $\left[v^{T} P v\right]=\min$. The functional and stochastic models of the adjustment computations are as follows:

$$
\begin{gathered}
l+v=A x \\
K_{l l}=\sigma_{0}^{2} P^{-1}
\end{gathered}
$$

In the Eq. (7), $l_{(\mathrm{nx})}$ is the measurements vector, $v_{(\mathrm{n} \times 1)}$ is the measurement residuals vector, $A_{(n x u)}$ is the (linearized) coefficients matrix, $x_{(\mathrm{ux} 1)}$ is the unknown quantities vector, $\sigma_{0}^{2}$ represents a priori variance, and $P_{(n \times n)}$ is the 
weight matrix. The following equation is obtained by the normal equations of adjustment computations:

$$
\begin{gathered}
\left(A^{T} P A\right) x-A^{T} P l=0 \\
N x-A^{T} P l=0
\end{gathered}
$$

where $N$ represents the normal equations matrix. The estimation of the unknown quantities is carried out by the following equation:

$x=\left(A^{T} P A\right)^{-1} A^{T} P l$

The condition of the $N$ matrix has a fundamental importance in the estimation of the unknown quantities. If there are fewer measurements than unknown quantities or the measurements are dependent on each other (linear dependency), the $N$ matrix has no Cayley inverse. In this case, the Moore-Penrose pseudoinverse, a generalization of the inverse matrix is employed to acquire a distinctive solution (Güllü et al. 2003, Akyilmaz 2007, Sisman 2014).

\section{TLS method}

The TLS approach assumes that both the measurements and coefficients matrix contain errors (which were ignored in the functional model of LS method) (Fig. 2 and Fig. 3). The functional model of the TLS method is expressed as:

$l+v=\left(A-V_{A}\right) x$

where $V_{A}(\mathrm{nxu})$ represents the correction values of the coefficients matrix and $v(\mathrm{n} \times 1)$ represents the correction values of the measurements. In the TLS method, the objection function is constructed as $\left[v^{T} v\right]+\left[\operatorname{vec} V_{A}^{T}\right.$ vec $\left.V_{A}\right]=\min$. instead of $\left[v^{T} v\right]=$ $\min$.

where vec represents vectoral operation.

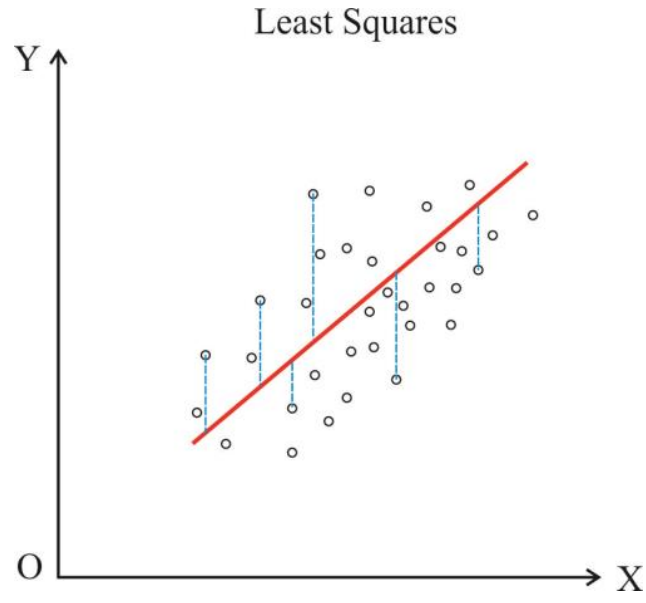

Fig. 2 LS method.

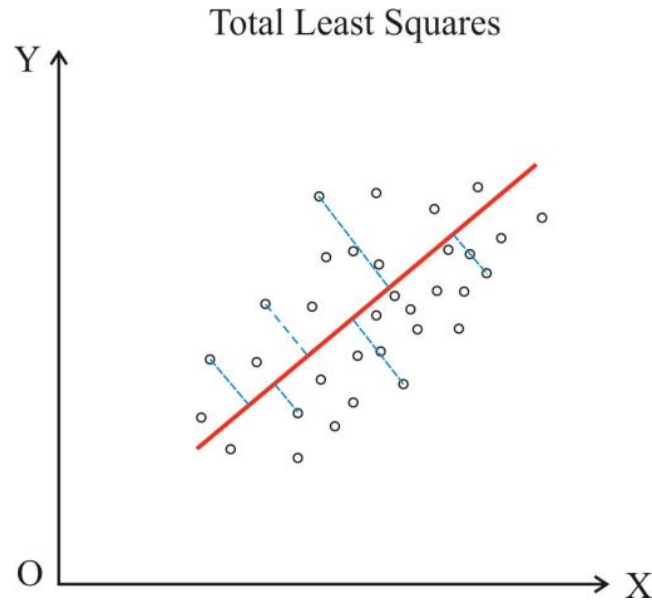

Fig.3 TLS method.

After $\left\|\left[\tilde{V}_{A} ; \tilde{v}\right]\right\|_{F}$ minimization procedure, the estimation of unknown parameters $(x)$ becomes as follows in TLS method.

$l+\tilde{v}=\left(A-\tilde{V}_{A}\right) x$

By merging $A$ and $l$ matrices, which consist of erroneous values, and by changing the expanded $[A ; l]$ matrix according to the Frobenius norm or reducing its rank, the following expression is obtained.

$[A ; l]-[\tilde{A} ; \tilde{l}]=\left[\tilde{V}_{A}-\tilde{v}\right]=\sigma_{u+1} U_{u+1} V_{u+1}^{T}$

When the Eq. (12) is reorganized, the following equation is obtained:

$$
\begin{aligned}
& {\left[A-V_{A} ; l-v\right]=[\tilde{A} ; \tilde{l}]=U_{u+1} \sigma_{u+1} V_{u+1}^{T}} \\
& \tilde{A} x-\tilde{l}=0
\end{aligned}
$$


If the Eq. (14) is reorganized, the following equation is obtained:

$$
\left[\begin{array}{ll}
\tilde{A} & \tilde{l}
\end{array}\right]\left[\begin{array}{c}
x \\
-1
\end{array}\right]=0
$$

In the Singular Value Decomposition (SVD) method, in order for the latest component to be (-1), $V_{u+1}$ is divided by its counterpart with opposite sign. The unknown quantities vector becomes as follows:

$x=-\frac{1}{V_{u+1, u+1}}\left[\begin{array}{lll}V_{1, u+1} & V_{2, u+1} \ldots & V_{u, u+1}\end{array}\right]^{T}$

Furthermore, if the TLS normal equations are written, it becomes as follows:

$\left(A^{T} P A-\sigma_{u+1}^{2} I\right) x=A^{T} P l$

The solution of the TLS normal equations is obtained as follows:

$x=\left(A^{T} P A-\sigma_{u+1}^{2} I\right)^{-1} A^{T} P l$

Thus, the estimation values of the unknown quantities are calculated with the TLS method (Felus 2004, Markovsky and Van Huffel 2005, Akyilmaz 2007).

\section{WTLS method}

The proper weighting (stochastic) model is crucial in the adjustment computations, because the measurements used in forming the functional model may not share the same precision. The weight of a measurement is scaled by its precision and it represents relative value of the measurement according to the other measurements. The amount of the corrections applied to measurements during the adjustment computations are controlled by the weights (assigning a higher weight for a more precise measurement). The functional model of the WTLS method (defining the adjustment condition) is constructed by Eq. (10) as:

$\left[\begin{array}{c}v \\ \operatorname{vec}\left(V_{A}\right)\end{array}\right] \sim\left(\left[\begin{array}{l}0 \\ 0\end{array}\right] \sigma_{0}^{2}\left[\begin{array}{cc}Q_{l} & 0 \\ 0 & Q_{A}\end{array}\right]\right)$ where $\sigma_{0}^{2}$ represents a priori variance, $Q_{l}(n \times n)$ represents the cofactor matrix of $l$ measurements, and $Q_{A}$ (nuxnu)represents the cofactor matrix of $A$ coefficients matrix (Van Huffel and Vandewalle 1991, Aydin 2016).

$P=Q_{l}^{-1}$
$P_{A}=Q_{A}^{-1}$

The objection function of the WTLS method can be constructed as $\left[v^{T} P v\right]+\left[v e c V_{A}^{T} P_{A} v e c V_{A}\right]=\min$. In the WTLS method, the measurements and the coefficients matrices receive corrections and it has an iterative feature because the initial weights are defined in a random manner. Initially, the estimation of the parameters is obtained with the LS method. The iteration procedure continues until the difference between the unknown elements is reduced until an acceptable value $\left(x_{i}-x_{i-1}\right)$. When iteration is completed, the estimated values of the unknown quantities give the WTLS solution. The stages of the WTLS solution:

Step 1: The estimation of the unknown quantities with LS method;

$x=\left(A^{T} P A\right)^{-1} A^{T} P l$

Step 2: Kronecker product $(\otimes)$ operation on the unknown quantities vector and the identity matrix;

$\hat{x}_{0}=x \otimes I$

Step 3: Iteration procedure;

For $i$

$$
\begin{aligned}
& Q_{i}=Q_{l}+\hat{x}_{i-1}^{T} Q_{A} \hat{x}_{i-1} \\
& \operatorname{vec}\left(V_{A}^{i}\right)=-Q_{A} \hat{x}_{i-1} Q_{i}^{-1}\left(l-A \hat{x}_{i-1}\right) \\
& \widehat{V}_{A}^{i}=\operatorname{reshape}\left[\operatorname{vec}\left(V_{A}^{i}\right)\right] \\
& \hat{A}_{i}=A-\hat{V}_{A}^{i} \\
& \hat{x}_{i}=\left(\hat{A}_{i}^{T} Q_{i}^{-1} \hat{A}_{i}\right)^{-1} \hat{A}_{i}^{T} Q_{i}^{-1}\left(l-V_{A}^{i} \hat{x}_{i-1}\right) \\
& \lambda_{i}=Q_{i}^{-1}\left(l-A \hat{x}_{i}\right)
\end{aligned}
$$

end if $\left\|\hat{x}_{i}-\hat{x}_{i-1}\right\|<\varepsilon$

Step 4: Variance calculation;

$\sigma_{0}^{2}=\frac{\lambda^{T}(l-A x)}{n-u}$ 
Step 5: Calculation of the Variance-Covariance matrix;

$$
C_{x}=\sigma_{0}^{2}\left(\hat{A}_{i}^{T} Q_{i}^{-1} \hat{A}_{i}\right)^{-1}
$$

(Markovsky and Van Huffel 2006, Jazaeri et al. 2013, Wang et al. 2016).

\section{Test Area, Source Data and Evaluation Procedure}

The 3D datum transformation application was carried out over a $\sim 57000-\mathrm{km} 2(270 \times 210 \mathrm{~km})$ test area covering eight provinces of Turkey which are Afyonkarahisar, Bilecik, Burdur, Denizli, Eskisehir, Isparta, Kutahya, and Usak, within the geographical limits:

$$
37.19^{\circ} \mathrm{N} \leq \phi \leq 40.44{ }^{\circ} \mathrm{N}, 28.74{ }^{\circ} \mathrm{E} \leq \lambda \leq 31.81{ }^{\circ} \mathrm{E} .
$$

The 3D datum transformation procedure refers to a source that comprised 56 control points (with known 3D coordinates - $1 \sigma$ standard deviations in WGS84 and 3D coordinates in ED50) (Fig. 4) belonging to TNFGN that has been established through surveys between 1997 and 1999. The positional accuracies of the points are about $1-3 \mathrm{~cm}$ whereas the relative accuracies are within the range of 0.1 - 0.01 ppm (GCM 2014).

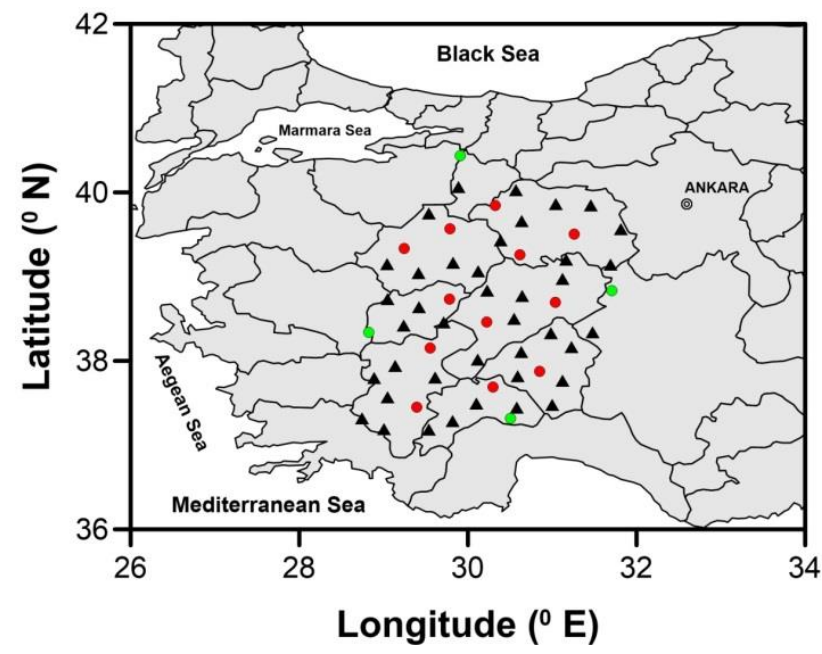

Fig. 4 Spatial distribution of control points within the test area.

The performance evaluation of the LS, TLS, and WTLS methods focused on the 3D coordinate differences. The coordinate differences were inquired by root-mean-square error (RMSE) value due to its appropriateness for comparing small differences between known and transformed coordinates (Yilmaz and Gullu 2014). RMSE is expressed as:

$R M S E=\sqrt{\left(\frac{1}{p}\right) \sum_{i=1}^{p}\left[(\mathrm{X}, \mathrm{Y}, \mathrm{Z})_{\mathrm{known}}-(\mathrm{X}, \mathrm{Y}, \mathrm{Z})_{\text {transform }}\right]^{2}}$

where $p$ indicates the number of the points.

\section{Comparative Transformation Study}

The source dataset (56 TNFGN points) was arbitrarily classified into two sub-sets as: reference (40 points denoted by black triangles in Fig. 4 , for the modelling procedure) and check (16 points denoted by red and green circles in Fig. 4, for the comparison procedure). The reference points covered the test area from outside. 12 check points (red circles) were selected to compose an interpolation task and 4 check points (green circles) were selected to compose an extrapolation task considering the geodetic network constituted by the reference dataset (Fig. 4). The classification was done to ensure that each dataset was representative of all possible variations of the source dataset.

The 3D datum transformation procedure consisted of two processes. The first process implied the transformation parameters estimation by the known 3D coordinates in both datum. In the second process, the estimated transformation parameters were used to transform the 3D coordinates of the points (that are not used in the first stage) from the source datum to the target datum.

The reference points were used for determining the seven parameters (three translation parameters, three rotation angles and a scale ratio) for the 3D datum transformation. The performance of the LS, TLS, and WTLS approaches are evaluated by the comparison of the known and the transformed 3D coordinates of the check points. Based on the LS, TLS, and WTLS methods, the computations were conducted with MATLAB $9.1^{\circ}$ software.

The transformation parameters estimated by the LS, TLS, and WTLS methods using 
40 reference points whose coordinates are known in WGS84 and ED50 datum, are given in Table 1.

Table 1 Estimated transformation parameters (WGS84

\begin{tabular}{lrrr}
\multicolumn{4}{c}{$\rightarrow$ ED50). } \\
\hline Parameters & \multicolumn{1}{c}{ LS } & \multicolumn{1}{c}{ TLS } & \multicolumn{1}{c}{ WTLS } \\
\hline$t_{x}(m)$. & 84.90493791 & 84.90493787 & 84.87421674 \\
$t_{y}(m)$. & 104.02871052 & 104.02871294 & 103.94531728 \\
$t_{z}(m)$. & 127.52388161 & 127.52388300 & 127.50569539 \\
$\varepsilon_{x}(")$ & -0.00000083 & -0.00000083 & -0.00000083 \\
$\varepsilon_{y}(")$ & 0 & 0 & 0 \\
$\varepsilon_{z}(")$ & 0.00000194 & 0.00000194 & 0.00000194 \\
$k(p p m)$ & 0.99999894 & 0.99999894 & 0.99999894
\end{tabular}

The coordinates of the 16 check points (12 interpolation points and 4 extrapolation points) in WGS84 datum were transformed into ED50 datum by using the transformation parameters estimated. The differences between the coordinates transformed with the known coordinates $\left(\Delta_{x, y, z}\right)$ of 16 check points were calculated, and the statistical values for interpolation and extrapolation are given in Tables 2, 3, and 4.

Table 2 The 3D differences and statistics based on the LS method (units in $\mathrm{m}$ ).

\begin{tabular}{|c|c|c|c|c|}
\hline & \multirow[t]{2}{*}{ Point } & \multicolumn{3}{|c|}{ LS Method } \\
\hline & & $\Delta \mathrm{x}$ & $\Delta y$ & $\Delta \mathrm{z}$ \\
\hline \multirow{15}{*}{ 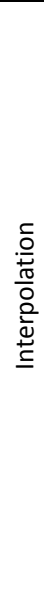 } & 1 & 0.0092 & 0.0093 & 0.0047 \\
\hline & 2 & -0.0087 & 0.0110 & -0.0065 \\
\hline & 3 & -0.0005 & 0.0036 & -0.0032 \\
\hline & 4 & -0.0108 & 0.0075 & 0.0066 \\
\hline & 5 & 0.0028 & -0.0048 & -0.0053 \\
\hline & 6 & 0.0035 & 0.0120 & 0.0095 \\
\hline & 7 & -0.0040 & -0.0035 & -0.0040 \\
\hline & 8 & 0.0095 & 0.0102 & 0.0044 \\
\hline & 9 & -0.0128 & 0.0017 & -0.0053 \\
\hline & 10 & 0.0029 & 0.0028 & 0.0101 \\
\hline & 11 & -0.0129 & -0.0063 & -0.0022 \\
\hline & 12 & 0.0121 & 0.0033 & 0.0132 \\
\hline & Min & -0.0129 & -0.0063 & -0.0065 \\
\hline & Max & 0.0121 & 0.0120 & 0.0132 \\
\hline & Mean & -0.0008 & 0.0039 & 0.0018 \\
\hline \multirow{7}{*}{ 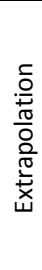 } & 13 & -0.0049 & -0.0031 & -0.0033 \\
\hline & 14 & 0.0100 & -0.0033 & -0.0079 \\
\hline & 15 & -0.0140 & -0.0044 & -0.0033 \\
\hline & 16 & 0.0146 & -0.0147 & -0.0062 \\
\hline & Min & -0.0140 & -0.0147 & -0.0079 \\
\hline & Max & 0.0146 & -0.0031 & -0.0033 \\
\hline & Mean & 0.0014 & -0.0064 & -0.0052 \\
\hline
\end{tabular}

Table 3 The 3D differences and statistics based on the TLS method (units in $\mathrm{m}$ ).

\begin{tabular}{|c|c|c|c|c|}
\hline & \multirow[t]{2}{*}{ Point } & \multicolumn{3}{|c|}{ TLS Method } \\
\hline & & $\Delta \mathrm{x}$ & $\Delta y$ & $\Delta z$ \\
\hline \multirow{15}{*}{ 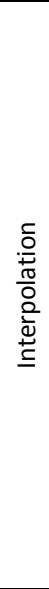 } & 1 & 0.0092 & 0.0093 & 0.0047 \\
\hline & 2 & -0.0087 & 0.0110 & -0.0065 \\
\hline & 3 & -0.0005 & 0.0036 & -0.0032 \\
\hline & 4 & -0.0108 & 0.0075 & 0.0066 \\
\hline & 5 & 0.0028 & -0.0048 & -0.0053 \\
\hline & 6 & 0.0035 & 0.0120 & 0.0095 \\
\hline & 7 & -0.0040 & -0.0035 & -0.0040 \\
\hline & 8 & 0.0095 & 0.0102 & 0.0044 \\
\hline & 9 & -0.0128 & 0.0017 & -0.0053 \\
\hline & 10 & 0.0029 & 0.0028 & 0.0101 \\
\hline & 11 & -0.0129 & -0.0063 & -0.0022 \\
\hline & 12 & 0.0121 & 0.0033 & 0.0132 \\
\hline & Min & -0.0129 & -0.0063 & -0.0065 \\
\hline & Max & 0.0121 & 0.0120 & 0.0132 \\
\hline & Mean & -0.0008 & 0.0039 & 0.0018 \\
\hline \multirow{7}{*}{ 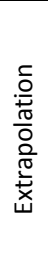 } & 13 & -0.0049 & -0.0031 & -0.0033 \\
\hline & 14 & 0.0100 & -0.0033 & -0.0079 \\
\hline & 15 & -0.0140 & -0.0044 & -0.0033 \\
\hline & 16 & 0.0146 & -0.0147 & -0.0062 \\
\hline & Min & -0.0140 & -0.0147 & -0.0079 \\
\hline & Max & 0.0146 & -0.0031 & -0.0033 \\
\hline & Mean & 0.0014 & -0.0064 & -0.0052 \\
\hline
\end{tabular}

Table 4 The 3D differences and statistics based on the WTLS method (units in $\mathrm{m}$ ).

\begin{tabular}{|c|c|c|c|c|}
\hline & \multirow[t]{2}{*}{ Point } & \multicolumn{3}{|c|}{ WTLS Method } \\
\hline & & $\Delta \mathrm{x}$ & $\Delta y$ & $\Delta \mathrm{z}$ \\
\hline \multirow{15}{*}{ 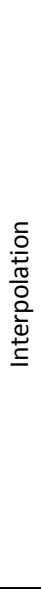 } & 1 & 0.0085 & 0.0086 & 0.0045 \\
\hline & 2 & -0.0076 & 0.0101 & -0.0051 \\
\hline & 3 & -0.0014 & 0.0040 & -0.0034 \\
\hline & 4 & -0.0095 & 0.0076 & 0.0051 \\
\hline & 5 & 0.0020 & -0.0049 & -0.0038 \\
\hline & 6 & 0.0031 & 0.0101 & 0.0078 \\
\hline & 7 & -0.0033 & -0.0040 & -0.0026 \\
\hline & 8 & 0.0103 & 0.0090 & 0.0035 \\
\hline & 9 & -0.0113 & 0.0017 & -0.0054 \\
\hline & 10 & 0.0023 & 0.0029 & 0.0091 \\
\hline & 11 & -0.0134 & -0.0059 & -0.0015 \\
\hline & 12 & 0.0122 & 0.0031 & 0.0130 \\
\hline & Min & -0.0134 & -0.0059 & -0.0054 \\
\hline & Max & 0.0122 & 0.0101 & 0.0130 \\
\hline & Mean & -0.0007 & 0.0035 & 0.0018 \\
\hline \multirow{7}{*}{ 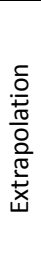 } & 13 & -0.0035 & -0.0037 & -0.0028 \\
\hline & 14 & 0.0098 & -0.0037 & -0.0055 \\
\hline & 15 & -0.0130 & -0.0041 & -0.0035 \\
\hline & 16 & 0.0125 & -0.0141 & -0.0065 \\
\hline & Min & -0.0130 & -0.0141 & -0.0065 \\
\hline & Max & 0.0125 & -0.0037 & -0.0028 \\
\hline & Mean & 0.0014 & -0.0064 & -0.0046 \\
\hline
\end{tabular}

To evaluate the performance of each 3D datum transformation, RMSE values were calculated for the 16 check points (Table 5). 
Table 5 RMSE values of LS, TLS, WTLS methods ( $p=16$ ) (units in $\mathrm{m}$ ).

\begin{tabular}{cccc}
\hline Method & \multicolumn{3}{c}{ RMSE } \\
\cline { 2 - 4 } & $\Delta \mathrm{x}$ & $\Delta \mathrm{y}$ & $\Delta \mathrm{z}$ \\
\hline LS & 0.0094 & 0.0074 & 0.0066 \\
TLS & 0.0094 & 0.0074 & 0.0066 \\
WTLS & 0.0088 & 0.0070 & 0.0059 \\
\hline
\end{tabular}

\section{Results and Conclusions}

In this study, the LS, TLS and WTLS methods were used to estimate geodetic transformation parameters for 3D datum transformation tasks. The results were compared in terms of RMSE by using the known 3D coordinates of the check points.

The analysis of the transformation parameters given in Table 1 reveals the similarity between the parameters based on the LS and TLS methods and it can be seen that the parameters based on the WTLS method are partially differing (at three translation parameters) from the other approaches. The evaluation of the coordinate differences of the check points presented in Tables 2, 3, and 4 shows that the LS and TLS methods gave the identical results. The WTLS method modelled the 3D coordinates of check points better than the other methods according to the mean values of $(-0.0007$ $\mathrm{m}, 0.0035 \mathrm{~m}, 0.0018 \mathrm{~m}$ for interpolation points; $0.0014 \mathrm{~m},-0.0064 \mathrm{~m},-0.0046 \mathrm{~m}$ for extrapolation points, respectively). By the evaluation of the results presented in Table 5, it can be considered that RMSEs of the coordinate differences of the check points remain identical when the LS or TLS method is utilized. In terms of RMSE, the WTLS method transformed the 3D coordinates of the check points more accurately $( \pm 0.0088 \mathrm{~m}, \pm 0.0070 \mathrm{~m}, \pm 0.0059$ $m$, respectively) with respect to the $L S$ and TLS methods,.

From the comparative results of evaluating the employment of the LS, TLS, and WTLS methods for the 3D datum transformation, the following conclusions can be drawn:

(1) The employment of the WTLS method is an effective transformation approach for the 3D datum transformation in geodetic applications.

(2) The WTLS method gives better results than LS and TLS methods for the 3D datum transformation when the coordinate precisions of reference points are poor and their correlations with check points are strong

(3) For the 3D datum transformation, the differences between the results using the TLS and LS methods are negligible.

(4) With improved geographical coverage and with more dense geodetic networks, more accurate (3D datum transformation) parameter estimation can be expected from the WTLS method and also from the LS and TLS methods.

(5) Both the analysis of the coordinate differences based on interpolation and extrapolation (check) points perform identically in the 3D datum transformation.

The coordinate transformations are frequently used in geodetic applications. In the 3D datum transformation applications, more accurate result may be required. In various cases, the traditional LS method will not usually offer a stable solution because of random property of the coefficients matrix and the contributions of the errors in the observed data in the transformation model. The TLS method is employed to overcome the first part of the problem. The WTLS method is developed for the second part of the problem.

The WTLS method is theoretically accurate than the LS and TLS methods for the 3D datum transformation owing to its proper weighting the coefficient (design) and the measurement matrices. Furthermore, the WTLS method is simple, flexible and exact, in contrast to the LS and TLS methods that try to realize the seamless 3D datum transformation.

\section{References}

Akyilmaz, O., 2007. Total least squares solution of coordinate transformation. Surv Rev, 39(303), 68-80.

Ayhan, ME., Demir, C., Lenk, O., Kilicoglu, A., Aktug, B., Acıkgoz, M., Firat, O., Sengun, Y.S., Cingoz, A., Gurdal, M.A., Kurt, A., Ocak, M., Turkezer, A., Yıldız, H., Bayazıt, N., Ata, M., Caglar, Y., Ozerkan, A., 2002. Turkish National Fundamental GPS Network-1999A (TNGFN-99A). J Mapp (Spec Issue) 16, 1-73 (in Turkish). 
Aydin, C., 2016. How to solve errors-in-variables model for coordinate transformations in a classical adjustment way?. J Geod Geoinf, 3, 49-57 (in Turkish).

Caglar, Y., 2005. National report of Turkey - 2005. Symposium of the IAG Subcommission for Europe (EUREF). Vienna. Austria.

Fang, X., 2011. Weighted Total Least Squares Solutions for Applications in Geodesy. PhD dissertation. Leibniz University. Hannover. Germany.

Fang, X., 2014. A total least squares solution for geodetic datum transformations. Acta Geod Geophys 49(2): 189-207.

Felus, Y.A., 2004. Application of Total Least Squares for spatial point process analysis. J Surv Eng, 130, 126133.

Felus, Y.A. and Schaffrin, B., 2005. Performing similarity transformations using the errors-in-variables-model. ASPRS 2005 Annual Conference, "Geospatial Goes Global: From Your Neighborhood to the Whole Planet", March 7-11, 2005, Baltimore, Maryland.

GCM, General Command of Mapping (2014) Turkish National Fundamental GPS Network.

Ghilani, C.D. and Wolf, P.R., 2006. Adjustment Computations: Spatial Data Analysis, 4th edn. Wiley, Hoboken.

Golub, G.H. and Van Loan C.F., 1980. An analysis of the Total Least Squares problem. SIAM J Numer Anal, 17, 883-893.

Gullu, M., Yilmaz, I., Erdogan, O.A., 2003. Geodetic Network Design. Afyon Kocatepe University Publications, Afyonkarahisar, (in Turkish).

Gullu, M., 2016. Soft computing model in geodetic coordinate transformation. AKU J Sci Eng, 16, 655659, (in Turkish).

Jazaeri, S., Amiri-Simkooei, A.R., Sharifi, M.A., 2013. Iterative algorithm for weighted total least squares adjustment. Surv Rev, 46, 19-27.
Lan, D., Hanwei, Z., Quingyong, Z., Ruopu, W., 2012. Correlation of coordinate transformation parameters. Geod Geodyn, 3, 34-38.

Li, B., Shen, Y., Zhang, X., Li, C., Lou, L., 2013. Seamless multivariate affine error-in-variables transformation and its application to map rectification. Int J Geogr Inf Sci , 27, 1572-1592.

Markovsky, I. and Van Huffel, S., 2005. High-performance numerical algorithms and software for structured total least squares. J Comput Appl Math, 180, 311 331.

Markovsky, I. and Van Huffel, S., 2006. On weighted structured total least squares. In: Lirkov I, Margenov S, Waśniewski J (eds) Large-Scale Scientific Computing. Lecture Notes in Computer Science, Vol. 3743. Springer, Berlin, Heidelberg, pp. 695-702.

Mahboub, V., 2012. On weighted total least-squares for geodetic transformations. J Geod, 86, 359-367.

Mihajlović, D. and Cvijetinović, Ž., 2016. Weighted coordinate transformation formulated by standard least-squares theory. Surv Rev. doi: 10.1080/00396265.2016.1173329.

NGA, National Geospatial-Intelligence Agency, 2002. Addendum to NIMA TR 8350.2: Implementation of the World Geodetic System 1984 (WGS 84) Reference Frame G1150.

Pearlman, M., Altamimi, Z., Beck, N., Forsberg, R., Gurtner, W., Kenyon, S., Behrend, D., Lemoine, F.G., Ma, C., Noll, C.E., Pavlis, E.C., Malkin, Z., Moore, A.W., Webb, F.H., Neilan, R.E., Ries, .JC, Rothacher, M., Willis, P., 2006. Global Geodetic Observing Systemconsiderations for the geodetic network infrastructure. Geomatica 60(2): 193-204.

Ren, Y., Lin, J., Zhu, J., Sun, B., Ye, S., 2015. Coordinate transformation uncertainly analysis in large-scale metrology. IEEE Trans Instrum Meas, 64, 2380-2388.

Schaffrin, B. and Feuls, Y., 2008. On the multivariate total least-squares approach to empirical coordinate transformations. Three algorithms. J Geod, 82, 272283. 
Schwieger, V., Lilje, M., Sarib, R., 2009. GNSS CORS Reference Frames and Services. $7^{\text {th }}$ FIG Regional Conference Spatial Data Serving People: Land Governance and the Environment - Building the Capacity, 19-22 October 2009, Hanoi, Vietnam.

Sisman, Y., 2014. Coordinate transformation of cadastral maps using different adjustment methods. J Chin Inst Eng, 37, 869-882.

Teunissen, P.J.G., 1988. The non-linear 2D symmetric Helmert transformation: an exact non-linear leastsquares solution. Bull Geod, 62, 1-15.

Tong, X.H., Jin, Y., Li, L., 2011. An improved weighted total least squares method with applications in linear fitting and coordinate transformation. J Surv Eng, 137, $120-128$

Turgut, B., 2010. A back-propagation artificial neural network approach for three-dimensional coordinate transformation. Sci Res Essays, 5, 3330-3335.

Van Huffel, S. and Vandewalle, J., 1991. The Total Least Squares Problem: Computational Aspects and Analysis. SIAM, Philadelphia.
Van Huffel, S., 1997. Recent advances in total least squares techniques and errors-in-variables modelling. Proceedings of the Second International Workshop on TLS and EIV, SIAM, Philadelphia.

Yilmaz, M. and Gullu, M., 2014. A comparative study for the estimation of geodetic point velocity by artificial neural networks. J Earth Syst Sci, 123, 791-808.

Wang, B., Li, J., Liu, C., 2016. A robust weighted total least squares algorithm and its geodetic applications. Stud Geophys Geod, 60, 177-194.

Zhao, J., 2016. Efficient weighted total least-squares solution for partial errors-in-variables model. Surv Rev. doi: 10.1080/00396265.2016.1180753. 